\section{Mediastinal Abscess following Sclerotherapy of Oesophageal Varices}

A 55-year-old female noninsulin-dependent diabetic suffering from biliary cirrhosis, portal hypertension, and oesophageal varices (third degree) underwent a cycle of endoscopic sclerotherapy with $0.5 \%$ Polidocanol for oesophageal varices after a massive hemorrhage. In the fourth session, a second-degree oesophageal varix which could be identified for a length of approximately $10 \mathrm{~cm}$ all the way to the ora serrata was successfully sclerosed with $20 \mathrm{ml}$ of $0.5 \%$ Polidocanol without significant bleeding. Approximately 30 minutes after the examination, the patient was found to have a temperature of up to $40{ }^{\circ} \mathrm{C}$ and complained of dysphagia. The chemical laboratory analysis showed that her C-reactive protein level had increased to $5.5 \mathrm{mg} / \mathrm{dl}$ with no leukocytosis. Four blood cultures failed to identify a causative pathogen. The CT image of the thorax showed a homogeneous space-occupying mass measuring approximately $4 \mathrm{~cm}$ in diameter, which was located retrocardially immediately over the diaphragm and exhibited a hypodense center with marginally hyperdense edges, causing a displacement of the oesophagus towards the left-hand lateral side without being sharply demareated from the latter. Despite the absence of air inclusions, a mediastinal abscess was suspected. The result of the differential diagnosis would also have been consistent with a hematoma in the process of formation (Figure 1). The oesophagogram obtained with a water-soluble contrast medium showed an impression of the oesophageal wall but no extraluminar leakage of contrast medium or fistulation (Figure 2). Following the administration of a triple combination antibiotic (metronidazol, gentamicin and ceftriaxon), the patient was soon symptom free. The (-reactive protein assay returned to normal within a week: the control CT scan taken after 13 days showed that the paraocsophageal mass had shrunk to a diameter of $2 \mathrm{~cm}$ (Figure 3 ).

The case deseribed above demonstrates that conservative therapy appears to be indicated even in abscess-forming processes of the mediastinum after endoscopic sclerotherapy for oesophageal varices (1).

M. Althoff'. J. Schoenemann', S. T. Wienhold', P. Spitz:

'Department of Internal Medicine and

Department of Radiology. St. Elisabeth Krankenhaus, Köln. Germany

\section{References}

1. Holn I: Komplikationen nach paravasaler Ösophaguswand Sklerosierung. Dissertation Ulm (1990) 15-17, 24-32.

\section{Corresponding Author}

J. Schoenemann. M.D.

Department of Internal Medicine

St. Elisabeth Krankenhaus

Werthmannstraße I

$50935 \mathrm{Köln}$

Germany

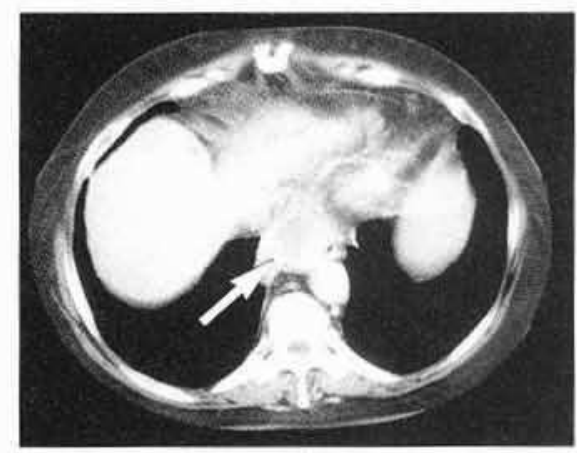

Figure 1: The CT image of the thorax taken on the day after sclerotherapy.
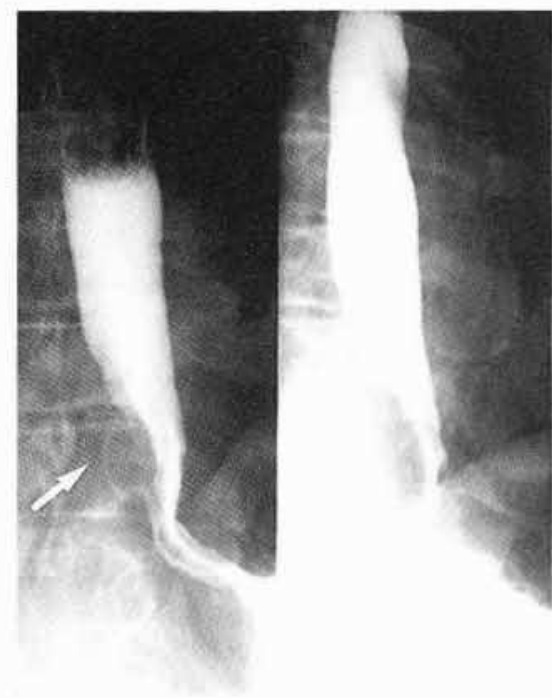

Figure 2: The oesophagus scan with a watersoluble contrast medium before therapy

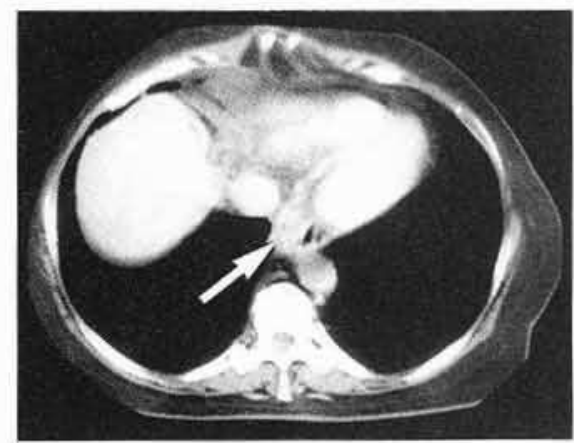

Figure 3: The CT image of the thorax taken thir teen days after sclerotherapy. 